\title{
Hypothyroid Goiter
}

National Cancer Institute

\section{Source}

National Cancer Institute. Hypothyroid Goiter. NCI Thesaurus. Code C131440.

Goiter associated with reduced thyroid hormone secretion. 